\title{
Author Index to Volume 2 (1992)
}

\author{
Boyle, O., 109 \\ Brox, B., 13 \\ Carlsson, P., 13 \\ Chen, T. S., 91 \\ Conway, P. P., 23, 161 \\ Doneen, P. M., 145 \\ Enkerlin, E. M., 153 \\ Ford, R., 101 \\ Gilleo, K., 37 \\ Goodall, A. J., 55 \\ Hong, S. Y., 169 \\ Jorgenson, D. M., 153 \\ Kim, C., 45, 61 \\ Kobayashi, T., 1 \\ Koh, A.-S., 101 \\ Livh, C., 13 \\ Lo, E. K., 55
}

O'Brian, C. O., 71

O'Grady, P., 45, 61

Ogunjimi, A. O., 109

Ogunjimi, A., 23

Ovacik, I. M., 119

Remer, D. S., 145

Schmidt, C. G., 1, 31

Seshadri, T., 101

Smith, S. J., 71

Tai, C. Y., 91

Uzsoy, R., 119

Whalley, D. C., 23, 109

Williams, D. J., 23, 109, 161

Wu, M. C., 91

Yih, Y., 137

Yin, N-C., 137

Young, R. E., 45, 61

Ziegler, F. S., 145 